\title{
Síndrome cri du chat: un maullido del gato.
}

(Cri du chat syndrome: a cat meow.)

\author{
Natalia Quesada Zaragoza \\ Universidad de Jaén (España) \\ nataliaques28@gmail.com
}

Fecha recepción: 01-05-2021

Páginas 118-137

Fecha aceptación: 25-05-2021

\section{Resumen.}

El síndrome del maullido de gato es una enfermedad hereditaria rara que se caracteriza por el hecho de que el niño afectado, bebé lactante, tiene un llanto similar al maullido de un gato (grito de un gato = cri du chat). El síndrome del maullido de gato está causado por una alteración específica del material genético: la pérdida (deleción) deuna parte de las estructuras filiformes del núcleo celular que portan el material genético (uno de los brazos de uno de los cromosomas: el brazo corto del cromosoma 5). El maullido de gato puede caracterizarse por alteraciones físicas y psicomotoras ya que se ralentizan. Suelen tener un peso extremadamente bajo tras el parto. El apoyo físico y mental temprano es decisivo para estos niños. La voz de los niños con síndrome del maullido de gato suele diferenciarse más a medida que crecen y el desarrollo del lenguaje suele retrasarse considerablemente.

Palabras clave: cri du chat; enfermedad hereditaria; cromosoma 5; alteraciones; llanto

\section{Abstract.}

The cat's meow syndrome is a rare hereditary disease characterized by the fact that the affected child, infant baby, has a cry similar to the meow of a cat (cry of a cat = cri du chat). The cat meow syndrome is caused by a specific alteration of the genetic material: the loss (deletion) of a part of the filiform structures of the cell nucleus that carry the genetic material (one of the arms of one of the chromosomes: the short arm of chromosome 5). The cat meow can be characterized by physical and psychomotor alterations since they slow down. They usually have an extremely low weight after childbirth. Earlyphysical and mental support is decisive for these children. The voice of children with cat meow syndrome tends to become more differentiated as they grow older and the development of language is often considerably delayed.

Keywords: cri du chat; hereditary disease; Chromosome 5; alterations; crying 


\section{1.-Introducción.}

El Síndrome de Maullido de Gato (Cri du chat) fue descrito a través de análisis citogenético. Es un trastorno relativamente raro y afecta uno de cada 20,000 a 50,000 nacidos vivos. La incidencia en las mujeres es ligeramente superior a los hombres, no han sido establecidas diferencias entre las razas o zonas geográficas. El llanto que es similar al maullido de un gato, suele considerarse como diagnóstico, que desaparece en los primeros años de vida, haciendo el diagnóstico más difícil en niños mayores.

Se caracteriza por una variedad de alteraciones físicas y psicomotoras. No hay tratamiento específico para pacientes con este síndrome, sin embargo los programas de rehabilitación deben ser empezados tan pronto como sea posible.

Este síndrome fue descubierto por el Dr. Lejeune en 1963. El término de "5p-" es usado por los genetistas para describir la pérdida de material genético del brazo cortoen el cromosoma del par 5. Las posibilidades de sufrir este síndrome son de 1 por cada 50.000 niños nacidos, existiendo alrededor de 900 afectados en España.

Los motivos que causan esta pérdida, en un $80-85 \%$ de los casos es fortuito, en cambio, el $15-20 \%$ restante es debido a una traslocación heredada, generalmente, en la madre. El síndrome del maullido de gato está causado por una alteración específica del material genético (mutación).

En el núcleo de la célula, se encuentran unas estructuras filiformes denominadas cromosomas que portan el material genético. Un ser humano cuenta normalmente con 46 pares de cromosomas. El síndrome del maullido de gato está causado por la pérdida de una parte (deleción) del cromosoma 5, mediante la cual se produce unaestructura divergente (aberración cromosómica). Esta alteración del material genético en los seres humanos con síndrome del maullido de gato puede presentarse por diferentes causas:

- $\quad$ Puede aparecer de manera espontánea tras la fecundación durante la división celular del óvulo (mutación espontánea).

- $\quad$ O ser consecuencia de la herencia genética.

Cuando el síndrome del maullido de gato está causado por la alteración cromosómica transmitida por herencia, se produce mediante la denominada translocación balanceada (translocación = traspaso de una parte del cromosoma a otro cromosoma). Esto significa que si un niño ha heredado el síndrome del maullido de gato, uno de los progenitores también presenta la alteración estructural del cromosoma 5, aunque esté sano, ya que: laparte que falta del cromosoma 5 (y la consiguiente información genética) no se ha perdidoen su caso, sino que se ha trasladado a otro cromosoma; es decir, la información genéticaestá disponible y simplemente se encuentra en otro lugar. Esta alteración no provoca ningún síntoma para el padre. Sin embargo, cuando el progenitor afectado transmite el cromosoma dañado a su hijo, este desarrolla el síndrome del 
maullido de gato. Aproximadamente entre el 10 y $15 \%$ de los casos tiene su origen en la vía hereditária.

\section{2.-Justificación.}

En los últimos veinte años se ha producido una mejora en el cuidado médico y social, que ha incrementado la esperanza de vida de personas con enfermedades limitantes. Sin embargo, algunos colectivos continúan siendo vulnerables y requieren una atención especial que asegure una adecuada cobertura de necesidades específicas tanto en salud general como en salud oral.

La salud es entendida como un "estado de completo bienestar físico, mental y social". El funcionamiento humano está influido por cualquier condición que altere su salud física o mental. Los efectos de la salud física y mental sobre el funcionamiento de la persona pueden oscilar desde muy facilitadores a muy inhibidores. Por otro lado, los ambientes también determinan el grado en que la persona puede funcionar y participar, o pueden fracasar en proporcionar la protección y apoyos apropiados.

En 2002, la AAMR (American Association on Mental Retardation) resalta la importancia de los apoyos, entendiendo éstos como los recursos y estrategias que pretenden promover el desarrollo, educación, salud, intereses y bienestar personal de una persona y que mejoran el funcionamiento individual. La evaluación de las necesidades de apoyo puede tener una importante relevancia si se realiza con fin de planificación de apoyos.

Se estima que actualmente existen cerca de cinco millones de personas con discapacidad en España. Estas poblaciones con necesidades especiales incluyen individuos con discapacidad psíquica asociada a enfermedades genéticas raras.

La sociedad cada vez es más consciente de la importancia de la salud oral en grupos desfavorecidos y con necesidades especiales, pero a pesar de ello, siguen existiendo numerosas barreras de acceso a la salud oral.

Las personas que sufren enfermedades raras tienen los mismos derechos e idénticos estándares de salud y cuidado que el resto de la población, y sin embargo existe evidencia de una atención odontológica inadecuada hacia estos pacientes y una experiencia en salud oral deficitária.

La atención sanitaria engloba más que un diagnóstico o un tratamiento. Un aspecto esencial relacionado con la calidad de la atención sanitaria prestada a las personas con enfermedades raras viene dado por el trato personal con el médico y el resto de profesionales sanitários.

El reciente trabajo de campo realizado por la Federación Nacional de Enfermedades Raras (FEDER), incluyó un total de 715 individuos afectados con enfermedades de baja prevalencia. Se encontró que el $47,3 \%$ de ellos se sentían insatisfechos en líneas generales, con la atención sanitaria recibida. La principal causa detectada fue el 
desconocimiento de la enfermedad por parte de los profesionalessanitarios, seguido de la inadecuación de los tratamientos prescritos, la descoordinación entre servicios sanitarios y entre administraciones o los desplazamientos que hay que realizar para recibir el tratamiento que necesitan.

Según el informe de EURODIS (2008), España es el país con mayor porcentajede insatisfacción con los servicios médicos de los pacientes con determinadas enfermedades raras en Europa. Una de las percepciones extraídas de los cuestionarios realizados a padres y/o tutores legales de los pacientes afectados, fue que las enfermedades raras provocan miedo y desesperanza en los profesionales sanitarios, ya que necesitan más tiempo de atención; tiempo que dichos profesionales no disponen y tienden a emplear con pacientes menos complejos y con mejor pronóstico.

Dada la baja incidencia de estas enfermedades, prácticamente son desconocidas por la sociedad, y en ocasiones también por los propios profesionales médicos. De este modo, concluyen que la información, la sensibilización, la coordinación y el establecimiento de protocolos pueden reducir las situaciones de estrés y conflicto y facilitar la comprensión tanto de estos procesos.

Unos de los objetivos principales en cuanto a atención sanitaria marcados en los planes de acción de la Junta de Andalucía responde a la generación de formación e información sobre las enfermedades raras y las pautas más apropiadas de relación y atención.

La formación de los profesionales, así como la información y sensibilidad de la sociedad son elementos necesarios, que redundan en una mejor comprensión de los problemas, en la búsqueda de soluciones compartidas y en el logro de una sociedad más equitativa.

Se hace imprescindible la promoción de intervenciones y estudios que, mediante la evaluación exhaustiva de la patología craneofacial y orofacial del síndrome de Maullido de Gato, mejoren el conocimiento y la información acerca del mismo, indicandoel camino hacia la atención en salud bucodental satisfactoria de los mismos.

\section{3.-Conceptualización.}

El Síndrome del Maullido del Gato, se puede clasificar en la categoría de anomalías estructurales cromosómicas. La fractura del cromosoma podría ser debido a factores ambientales como virus, radiaciones o fármacos. El resultado de la anomalía depende de los fragmentos, produciendo una minusvalía psíquica. Es un grupo de síntomas que resultan de la supresión de una parte del cromosoma número 5.

Descrito por Lejeune en 1963, entre 1 en 20.000 y 1 en 50.000 bebés se ven afectados por este síndrome que puede ser responsable de hasta el $1 \%$ de casos de retardomental 
severo. En el territorio español y, según fuentes de ASIMAGA el número de afectados estará alrededor de 65070 casos.

El diagnóstico es llevado a cabo a través del estudio cromosómico, primero del paciente y luego de los padres, para conocer el origen del mismo. Es una comosomopatía estructural, caracterizada por una fractura (deleción) del cromosoma. En la mayoría de los casos, se produce en ellos mismo, aunque en un grupo pequeño la heredan de los padres.

Por lo general, nacen con un peso bajo (menor a 2,5 Kg.), el crecimiento es lento, hay una hipotonía generalizada (son blanditos), microcefalia, cara redondita, los ojitos separados, la inclinación de los ojos hacia abajo, puede haber estrabismo. Un 30\% de losafectados pueden presentar una cardiopatía (de diferentes tipos). En las manos se observala raya palmar única. Se describen varias anormalidades ocasionales, como labio y paladar hendido, miopía, hernia inguinal, ausencia de riñón y bazo, entre otras...Presenta llanto característico que recuerda al maullido de gato, por larigomalacia con hipoplasia de la epiglotis y relajación de los pliegues ariepiglóticos.

La voz característica del periodo neonatal desaparece en los pacientes de más edad. Predomina en las niñas, y al nacimiento suele llamar la atención el tamaño del cráneo, que contrasta con la cara redonda y llena. Los niños se desarrollan lentamente y permanecen muy retrasados en cuanto a su estática y psicomotricidad. Al aumentar la edad se acentúa el retraso de las capacidades intelectuales.

En cuanto a la evolución natural, los pacientes tienen a ser hiperactivos. Los niñosy niñas afectados, deben de ser estimulados desde pequeños, poner mucha atención en laetapa escolar y debe haber un apoyo familiar constante, con lo cual se logra un nivel socialy psicomotor de un niño o niña de cinco a seis años, con un vocabulario y estructura de oraciones adecuados para la comunicación.

\section{4.-Historia, etiología, tipología e incidencia.}

En el año 1963, Lejeune y Cols., realiza la primera descripción de este síndrome en conclusión a las observaciones realizadas en un grupo de niños con características clínicas y citogenéticas comunes consistentes en retraso mental, anomalías cráneofaciales y una deleción del brazo corto de un cromosoma del par 5. La causa del síndrome es una pérdida, denominada deleción, de material genético en el cromosoma 5.Más concretamente, existe una deleción en el brazo corto del cromosoma 5 (5 15.2 $5 p 15.3$ ), siendo el paciente heterocigoto (persona en la cual dos genes homólogos, alelos,de los cromosomas del mismo par son diferentes) para la deleción, ya que el homocigotoes inviable, es decir incompatible con la vida.

Cuanto mayor sea la pérdida de material genético, mayores, en cuantía y gravedad, serán el número de alteraciones; el coeficienteintelectual será menor al igual que su estatura y peso al nacer. Hasta el momento, el factorque origina, o permite, la alteración en esta región cromosómica se desconoce. Aun así, se cree que, en la mayoría de los 
casos, se debe a la pérdida de cierta información en el cromosoma 5 durante el desarrollo de un óvulo o esperma (Gametogénesis), hecho el cual no parece relacionarse con la edad de los padres, como ocurre en otros síndromes de estetipo.

\section{5.-Objetivos.}

1. Evaluación de las necesidades y dificultades odontológicas específicas de los pacientes con síndrome de maullido de gato, según los parámetros siguientes:

- $\quad$ Análisis descriptivo de las características fenotípicas.

- $\quad$ Análisis descriptivo de la patología oral.

- $\quad$ Estado dental.

- $\quad$ Estado periodontal.

- $\quad$ Estudio de su perfil de comportamiento y del manejo clínico odontológico.

2. Analizar las características craneofaciales mediante radiografía lateral de cráneo y cefalometría.

3. Valorar la flora periodontopatógena de los pacientes con síndrome de Maullido deGato, comparándola con un grupo de control sin el síndrome.

\section{6.-Clasificación de las estereotipias y de los comportamientos característicos en base a la modalidad sensorial alterada.}

Los aspectos más comunes que caracterizan los niños con síndrome del maullido de gato son:

- $\quad$ Típico llanto que recuerda al maullido del gato.

- $\quad$ Bajo peso, baja talla y microcefalia.

- $\quad$ Cara redonda en forma de luna llena.

- Hipotonía (el niño es más "flojo").

- $\quad$ Raíz nasal prominente.

- $\quad$ Orejas con implantación baja.

- $\quad$ Hipertelorismo, epicanto, rima del ojo con esquinas hacia abajo, estrabismo.

- $\quad$ Microretrognatia (mandíbula pequeña).

- $\quad$ Boca en forma de arco.

- $\quad$ Anormalidades de los dermatoglifos, un solo pliegue palmar.

Más raramente, se pueden observar:

- $\quad$ Problemas respiratorios (cianosis, asfixia).

- $\quad$ Problemas de alimentación (la succión no es lo suficientemente eficaz como para comer). 
- $\quad$ Infecciones del tracto respiratorio bastante frecuentes en los primeros años de vida.

- $\quad$ Malformaciones (especialmente renales y cardíacas).

a) Problemas sensoriales del tacto:

- $\quad$ Camina de puntillas.

- $\quad$ Es poco sensible a los estímulos dolorosos.

- Le molestan las caricias o los besos.

- $\quad$ Es extremadamente sensible al dolor.

- Mueve las manos y/o las choca contra la frente, la cara, o se golpea el rostro con las manos de lado.

- $\quad$ Golpea la cabeza contra superficies duras.

- $\quad$ Se provoca laceraciones profundas en el cutis.

- $\quad$ Se da bofetada, golpes, se muerde o se procura lesiones en algún modo.

b) Problemas sensoriales de la vista:

- $\quad$ Evita establecer contacto con los ojos.

- $\quad$ Mira las manos, los objetos o los detalles del entorno durante al menos 5 segundos consecutivos.

- $\quad$ Mueve rápidamente los dedos o las manos delante de los ojos durante unos segundos o más.

- $\quad$ Parece mirar cosas en el aire que sólo él puede ver.

- Mueve objetos casuales para hacerlos girar.

- $\quad$ Hace girar rápidamente balones y/o ruedas.

- $\quad$ Apila objetos con extrema precisión.

- $\quad$ Crea hilos con su saliva.

c) Problemas sensoriales del oído:

- $\quad$ Emiten sonidos con un timbre de voz muy agudo y/o alto o vocalizaciones por autoestimulación.

- $\quad$ Se golpea la cabeza o las orejas.

- $\quad$ Golpea los objetos para hacer ruido.

- $\quad$ "Se aísla en la música" o la escucha a alto volumen.

- Se tapa los oídos con las manos.

d) Los problemas sensoriales vestibulares:

- Gira sobre sí mismo o gira en círculo.

- $\quad$ Balancea el cuerpo mientras está sentado o de pie.

- $\quad$ Hace movimientos rápidos y bruscos cuando se desplaza.

- $\quad$ Salta mientras se mueve o se desplaza de un lugar a otro.

- $\quad$ Posturas extrañas cuando se sienta o se acuesta en posición al revés.

e) Problemas sensoriales del gusto y del olfato:

- $\quad$ Se niega a comer los alimentos que generalmente todos comen.

- $\quad$ Come cualquier cosa logre agarrar. 
- $\quad$ Lame objetos no comestibles.

- $\quad$ Percibe olores o huele objetos.

- $\quad$ Come mirando hacia el plato.

En el desarrollo psicomotor está severamente afectado en niños con síndrome de maullido de gato aunque investigaciones recientes ponen de manifiesto resultados más positivos y optimistas. Las principales dificultades se observan en la coordinación dinámica de los movimientos y en las habilidades motoras finas.

En cuanto al desarrollo del lenguaje se observan dos líneas de divergencia: una está relacionada con la diferencia entre la edad cronológica del niño y la presunta edad lingüística, que se hace mayor a medida que aumenta la edad. La otra línea de divergencia se sitúa entre la comprensión del lenguaje y el lenguaje expresivo que parecen ser muy limitadas, aunque en las habilidades de comunicación se observa un buen uso de las habilidades de la comunicación no verbal.

Por otro lado, con respecto a la hiperactividad y el déficit de atención se puede manifestar en diferentes formas y con varias intensidades, especialmente en los momentos en que el niño está más cansado o estresado, o también cuando busca la atención de los adultos. Al mismo tiempo se observa que el intervalo de atención a la tarea es muy bajo y que la distracción producida por el sonido y los estímulos visuales es muy alta.

También se puede establecer una relación entre percepción sensorial y comportamiento. La hiperacusia o la hipersensibilidad visual surgen de un déficit en el sistema nervioso central a nivel de integración y procesamiento de la información sensorial. Pues, la hipersensibilidad a los sonidos y a las imágenes es un fenómeno característico del síndrome del maullido de gato.

En cuanto a la sensibilidad táctil, se notan varios tipos de alteraciones: la sensibilidad al dolor está reducida y entonces el niño no llora o llora poco. La sensibilidad táctil suele ser más acentuada y por consiguiente un contacto ligero, como una caricia o el peinarse el cabello, puede resultar muy molesto.

\section{7.-Causas, incidencias y factores de riesgo.}

La causa del síndrome del maullido del gato es la supresión de cierta información en el cromosoma 5. Es probable que se supriman múltiples genes en dicho cromosoma. Uno de los genes suprimidos llamado telomerasa transcriptasa inversa (TERT, por sus siglas en inglés) está comprometido en el control del crecimiento celular y puede jugar un papel en la forma como se desarrollan algunas de las características de este síndrome. La causa de esta rara supresión cromosómica se desconoce, pero se cree que la mayoría de los casos se debe a la pérdida espontánea de una parte del cromosoma 5 durante el desarrollo de un óvulo o de un espermatozóide.

a) Síntomas: 
- $\quad$ Llanto de tono alto similar al de un gato.

- $\quad$ La facies suele ser redondeada, llena y mofletuda ("cara de luna").

- $\quad$ Peso bajo al nacer y crecimiento lento.

- $\quad$ Cabeza pequeña (microcefalia).

- $\quad$ Ojos separados (hipertelorismo).

- Inclinación de los ojos hacia abajo (fisuras palpebrales).

- Miopía y atrofia óptica.

- $\quad$ Quijada pequeña (micrognatia).

- $\quad$ Orejas de implantación baja.

- $\quad$ Excrecencia cutánea justo delante de la oreja.

- $\quad$ La raíz de la nariz está hundida.

- $\quad$ Dedos de las manos y pies parcialmente unidos por membranas.

- $\quad$ Un solo pliegue en la palma de la mano (pliegue simiesco).

- $\quad$ Pulgar aducido hacia el interior desarrollo lento o incompleto.

b) Características físicas y psicológicas:

- $\quad$ Llanto agudo al nacer (similar al maullido de un gato).

- $\quad$ Microcefalia (cabeza pequeña).

- $\quad$ Retraso en el crecimiento.

- Discapacidad intelectual.

- Dificultades para comunicarse.

c) Características de comportamiento:

- Marcado sentido del humor.

- $\quad$ Cariñosos y muy afectivos.

- Miedo a determinados objetos.

- Tímidos.

- $\quad$ Conductas desafiantes.

- $\quad$ Agresiones y autolesiones.

- $\quad$ Alteraciones a nivel psicofísico.

d) Complicaciones:

- Incapacidad de valerse por sí solo.

- Incapacidad de desenvolverse socialmente.

- $\quad$ La esperanza de vida no se puede evaluar con certeza, pero se describen casos de adultos con pocos casos de fallecimiento.

e) Evolución:

De los 2 a los 5 años, los niños con el síndrome mantienen la cara redondeada y la nariz corta, aunque se modifica en la adolescencia alargándose la cara y el puente nasal, se hace prominente. Son habituales las complicaciones respiratorias y de oídos que precisan incluso de ingreso hospitalario. Los cambios en la pubertad serán los típicos con desarrollo mamario, aparición de la menstruación, vello, voz grave... La mitad de los niños adquieren las habilidades verbales suficientes para comunicarse. Los niños afectados disfrutan relacionándose con otros niños, a menudo tienen buenos 
conocimientos sociales, sentido del humor y una excepcional memoria. En cuanto a los aprendizajes escolares, los estudios sonmuy escasos.

\section{8.-Cognición y lenguaje en niños Cri Du Chat.}

Según Carlin (1988), ofrece datos longitudinales sobre 31 individuos con CDC y datos transversales sobre otros 31 casos. En todos los individuos con CDC, se observa un retraso del crecimiento notable, microcefalia, un importante retraso psicomotor e infecciones respiratorias y óticas frecuentes. También encuentra hipotonía generalizada durante los primeros meses que posteriormente tiende a normalizarse en al menos el $50 \%$ de los casos si viene acompañada de entrenamiento precoz.

Las metas evolutivas que los afectados puedan alcanzar vendrán condicionadas por tres factores:

1. La magnitud del daño determinará el límite biológico y la posibilidad de alcanzar metas específicas de tipo físico, cognitivo, social y personal (Cerruti Mainadi, 2006).

2. La atención precoz suministrada así como el entrenamiento y/o enseñanza recibida porparte de profesionales especializados.

3. La respuesta del niño. Generalmente se asume que cuando el niño muestra interés porla interacción, curiosidad por el entorno y deseo de aprender, éstos son signos que hacenprever un mejor pronóstico y evolución (Choong, Watts, Little \& Beck, 2003).

En lo referido al desarrollo del lenguaje y la cognición es más reducido. Las observaciones y los registros confirman que el lenguajereceptivo es mejor que el lenguaje expresivo. Al analizar la fonética y fonología utilizada por los pacientes, se nota frecuentes sustituciones, omisiones y distorsiones. El número de consonantes usadas es pequeño y la cantidad de sílabas empleada también es restringida. Se sabe poco acerca de sus habilidades sintácticas, aunque algunas personas pueden expresarse haciendo uso dedos o más palabras para comunicarse (Cornish, Bramble, Munir \& Pigram, 1999; Cornish\& Munir, 1998).

Según Carlin (1988) el desarrollo de la palabra es posible en como mínimo el 50\% de individuos educados a domicilio y sometidos a una intervención precoz bien organizada. Con el tiempo se puede observar un aumento de la utilización combinada del habla, los signos mediantegestos y medios para-verbales de comunicación. Se cree que los individuos con CDC difícilmente llegan a expresarse únicamente por medio del habla y del lenguaje, aunque cualquier conclusión es prematura dada la escasa perspectiva disponible.

En cuanto al desarrollo académico, muy pocos lograrán competencias adecuadas en lectura y escritura y si las logran será a un nivel muy básico necesitando un refuerzo continuado para su mantenimiento. Normalmente, el grado de retraso motor condiciona el desarrollo cognitivo: cuanto mayor es el retraso motor peor es el funcionamiento intelectual y lingüístico (Cornish \& Pigram 1996). Un fenómeno 
reiteradamente observado es que lossignos fenotípicos se vuelven menos evidentes a media que los chicos se hacen mayores.La certeza de esta información nos llevaría a pensar que el desarrollo motor podría mejorar con la maduración y, por ende, el nivel funcional cognitivo también podría mejorar (Collins \& Eaton-Evans, 2001).

El área de desarrollo social se sabe que estos niños son capaces de establecer relaciones sociales con sus iguales, quedisfrutan con las situaciones de juego, pero no tienen conciencia de los riesgos y ejecutan acciones susceptibles de peligro y daño para su salud física. Cuando emiten juicios sobre las consecuencias de sus actos no son capaces de anticipar los riesgos y los resultados (Cornish, Bramble, Munir \& Pigram, 1999). Cornish \& Pigram (1996) describen otros rasgos clínicos negativos que conviene tener en cuenta a la hora de tratar a estos niños:

- $\quad$ Conducta hiperactiva (50\% de casos).

- $\quad$ Hiperactividad acompañada de agresividad.

- $\quad$ Conductas auto-lesivas.

- $\quad$ Movimientos repetitivos.

- $\quad$ Hipersensibilidad a los sonidos.

- $\quad$ Apego obsesivo a objetos y personas.

- $\quad$ Conductas desafiantes.

- $\quad$ Miedos injustificados.

- $\quad$ Reacciones anómala ante extraños.

- $\quad$ Timidez extrema.

\section{a) Esperanza y calidad de vida}

En la fase inicial posterior al descubrimiento y descripción del CDC (año 1963), las estimaciones de vida para estos niños eran muy escasas y muchos de ellos morían en los primeros años de vida. Una serie de datos recientes obtenidospor diversos investigadores en estudios longitudinales (Carlin, 1988); (Wilkins, Brown \&Wolf, 1980); (Wilkins, Brown, Nance \& Wolf, 1982) muestran que el pronóstico actuales claramente mejor por lo que respecta a la salud, al desarrollo psicológico y a la esperanza de vida.

Lo que preocupa a las familias es la alta probabilidad de que los niños con CDC sean incapaces de valerse por sí solos y que puedan desenvolverse socialmente. Existe la esperanza de que algunos de los síntomas se moderen conel paso del tiempo y sobre todo que los programas de entrenamiento rehabiliten las áreasmás deterioradas.

b) Intervención psicológica

El trabajo terapéutico de los CDC debería empezar desde los 3 meses, tomando en cuenta dos vertientes: terapia física para lograr la mayor independencia de movimientos posibles; y la estimulación temprana para desarrollar sus aptitudes y 
potencialintelectual. Uno de los aspectos que el especialista debe considerar es la evaluación de unfisioterapeuta, quien determinará si el niño requiere aparatos para desplazarse e incluso indicará si hay que practicar una intervención quirúrgica para modificar algún defecto. El propósito de este entrenamiento es que los CDC realicen todas aquellas actividades que les otorguen libertad de movimientos y autonomía personal, dentro de las limitaciones que el síndrome impone(Echeverría, 2000).

En los problemas cognitivos, de acuerdo a su edad y capacidad se trabaja con programas de computación especiales que mejoran su coordinación y memoria. El uso de estos recursosinformáticos está resultando muy eficaz para el aprendizaje y a su vez generan niveles demotivación altos.

Los CDC suelen mostrar algunas conductas muy disruptivas (Cerruti Mainardi, 2006) que deben ser intervenidas para dotar a los niños de modelos adecuados de conducta y comunicación (Dykens \& Clarke, 1997).

A nivel conductual se recomienda el uso de técnicas de modificación de conducta para reducir y/o eliminar las conductas inadecuadas. En el caso de quelas manifestaciones conductuales sean potencialmente peligrosas para el propio niño u otras personas, se valorará la posibilidad por un psiquiatra de introducir la medicación pertinente (Clarke \& Boer, 1998).

En el terreno psico-educativo, el área principal de intervención será el abordaje del retraso mental asociado al síndrome (Cornish, Bramble, Munir \& Pigram, 1999; Chang, Lin, Lin, Chen, Kao, Yeung et al. 2007). Las técnicas de estimulación cognitiva y logopédica pueden aportar avances significativos. El juego constituye una estrategia motivadora para la realización de las diferentes actividades. Éstas deben estar encaminadas a conseguir el éxito siguiendo un nivel creciente de dificultad. Un objetivo importante es el de establecer un canal comunicativo eficaz con el niño, lo que supondría un paso importante en la prevención de las conductas disruptivas, ya que conseguiría comunicar de forma eficaz sus necesidades o deseos, al tiempo que el educador también podría requerirle algunas cosas. Se aconseja (en ausencia de la expresión verbal), la confección de un libro con imágenes o fotografías para la identificación de acciones o personas.

\section{9.-Diagnóstico y evaluación. Posibilidades de prevención. Detección temprana, técnicas e instrumentos.}

-Diagnóstico y evaluación.

El diagnóstico inicial, o de sospecha, es clínico ante la presencia de un niño con el llanto característico, retraso en el crecimiento y las anomalías cráneo- faciales descritas. La confirmación del diagnóstico se realiza mediante el estudio del cariotipo, en el que se objetiva la pérdida de un fragmento del cromosoma 5. También, mediante el uso de técnicas de mapeo cromosómico muy finas, pueden identificarse las 
alteraciones específicas en las regiones 5p15.2-5p15.3, siendo diagnóstico definitivo derivado de dicho estudio cromosómico.

Un tipo de prueba genética más detallada, como el FISH, puede revelar la falta de una pequeña porción de este cromosoma 5 , no detectable mediante el cariotipo convencional. El diagnóstico prenatal del síndrome, mediante ecografía, es difícil aunquepuede sospecharse cuando se presentan anomalías graves y un marcado retraso del crecimiento intrauterino. En este caso podría indicarse una amniocentesis, en la que se obtendrían células fetales para la realización de un cariotipo en el que se podría detectar la anomalía cromosómica que confirmaría el diagnóstico.

A día de hoy, la investigación en técnicas de análisis molecular está permitiendo definir los límites de un cierto número de deleciones en el brazo corto del cromosoma 5 y comparar los signos clínicos observados en los pacientes. Esto nos permite explicar la disociación entre los diferentes elementos del síndrome, para el cual la zona exacta ha podido ser individualizada.

\section{-Prevención.}

Dado el desconocimiento de las causas de esta afección, la prevención no es posible. La única posibilidad al respecto está vinculada a la etiología genética del síndrome ya la detección de factores y poblaciones de riesgo, en los cuales existe un error en los cromosomas paternos.

Tras el nacimiento de un niño con este síndrome es importante el estudio de los padres, que nos orientará sobre las posibilidades de tener un segundo hijo afectado.El estudio del cariotipo de los padres es indispensable para poder estimar el riesgo de recurrencia de la anomalía. Este riesgo es muy pequeño (1\%), salvo que exista una anomalía previa en uno de los progenitores. Si se demuestra, mediante cariotipo, que unode los padres presenta una translocación, el riesgo de recurrencia oscila entre el 15 y el 25\%, siendo el riesgo teórico, de transmisión de la anomalía, del $50 \%$ en parejas en que uno de los dos esté afectado.

\section{-Pronóstico médico.}

La esperanza de vida de estos individuos está disminuida, aunque la mayoría alcanzan la edad adulta (alrededor de los 50 años). Este aspecto depende de la gravedad de las malformaciones asociadas (cardiopatía...). La norma es el retraso mental, aunque podemos decir que la mitad de los niños adquieren las habilidades verbales para comunicarse en los términos antes descritos. La estimulación precoz de la comunicación y del área motora ha mejorado el pronóstico de forma significativa.

Hace años era frecuente que los niños con este síndrome fuesen internados en instituciones junto a individuos con retraso mental severo. Desde principios de los años 80 se objetivó que estos niños, integrados en sus familias y con el beneficio de las técnicas de atención temprana, son capaces de realizar importantes progresos 
superando incluso las expectativas de los doctores que descubrieron por primera vez el síndrome.

Las características físicas de los individuos con este síndrome se vuelven menos aparentes con el tiempo. El epicantus se atenúa, la cara se alarga, se hace asimétrica y pierde su redondez. Los huesos faciales comienzan a modificarse en cuanto a su crecimiento relativo y no se hacen tan evidentes el hipertelorismo y la micrognatia. El llanto se hace más grave y desaparece el tono característico al alcanzar el año de edad. Lahipotonía tan notable en el lactante desaparece y los reflejos se hacen vivos. En la marcha,los pies arrastran por el suelo. El cabello se hace prematuramente gris. Suelen presentar infecciones de repetición, otitis medias y dificultades para alimentarse. A pesar de todos estos avances es todavía difícil ofrecer un pronóstico individual precisoen las deleciones del brazo corto del cromosoma 5 porque sujetos portadores de deleciones aparentemente iguales pueden tener fenotipos 0 características distintas.

\section{-Pronóstico psicopedagógico.}

El pronóstico en estos casos debe ser realista. Nadie puede determinar de antemano cuáles van a ser los logros de desarrollo que puede alcanzar, por lo que deben tomarse todas aquellas iniciativas que puedan maximizar su potencial de desarrollo y posibilitarle la oportunidad de tener una vida plena y lo más normalizada posible.

Los equipos de atención temprana, orientarán a las familias sobre los recursos y actuaciones de cara a una intervención psicoeducativa a través de programas de atencióntemprana para establecer un pronóstico más favorable. Dichos programas deben incluir aspectos psicomotrices, sensoriales, cognitivos, comunicativos, socioafectivos, así como diseños de modificación de conducta cuando proceda.

La familia debe obtener el apoyo necesario, no sólo para comprender y aceptar la realidad de la persona afectada, sino para participar activamente dentro del programa de atención temprana. La colaboración de educadores, técnicos y familia es totalmente imprescindible, pero en concreto la familia es singularmente decisivo durante los primeros años de vida, donde deberán seguir las instrucciones de estimulación que les marquen los especialistas conforme a su evaluación de las necesidades y posibilidades concretas cada caso particular.

De cara a esta colaboración, un principio fundamental son las actividades que persigan favorecer el desarrollo del niño que nunca deben de llevarse a cabo con una actitud mecánica, forzada o en situaciones de cansancio, baja receptividad o desinterés del niño. Es fundamental que el niño esté motivado y disfrute de las actividades para lo cual debe evaluarse cuidadosamente la duración de las sesiones más adecuada, el grado de dificultadque representan para él, nuestras reacciones frente a las dificultades que pueda manifestar y como establecer los pasos sucesivos para superarlas. 
En lo relativo al desarrollo cognitivo, éste se va a ver facilitado por contextos de aprendizaje que le ofrezcan una estimulación multisensorial. No obstante, un elemento previo y fundamental del programa en este ámbito va a ser las actividades destinadas a desarrollar las capacidades atencionales del niño. Lógicamente, en este sentido, el objetivo inicial debe de ser el establecimiento y mantenimiento del contacto visual, primero hacia las personas que cuidan de él y luego sobre modificaciones contextuales que introducimos en su entorno.

En cuanto a su capacidad comunicativa, sus primeras palabras aparecen entre los 3 y los 6 años y que, aunque algunos podrán construir oraciones completas, en otros casos sólo serán capaces de utilizar unas pocas palabras aisladas. Su capacidad comunicativa debe ser objeto de constante estimulación, favoreciendo la complementación de las expresiones verbales y gestuales, aprovechando para ello todas las circunstancias cotidianas de interacción para acompañarlas y enriquecerlas con expresiones verbales e impulsar la adquisición y uso por parte del niñode los elementos lingüísticos en sus comunicaciones, aportándole ejemplos adaptados, ocasiones de utilización y estímulo ante sus ejecuciones.

En general, a la hora de diseñar el programa debe considerarse la funcionalidad de los aprendizajes planteados de cara a la mejor inclusión en su entorno. Es importante adecuar el ritmo de aprendizaje y la correcta consolidación de cada paso a la hora plantearse un nuevo objetivo. A medio plazo podemos establecer los siguientes elementos como fundamentales de cara a maximizar las posibilidades de autodeterminación, autonomía personal e inclusión social del individuo:

- $\quad$ Independencia en relación con aspectos básicos del aseo e higiene personal, control deesfínteres, ciclos de vigilia-sueño apropiados y estables, pautas de alimentación.

- $\quad$ Autonomía o colaboración activa respecto al manejo del vestuario y limpieza de su entorno vital.

- Hábitos en la mesa y en otras situaciones afectadas por los usos y costumbres de suentorno social.

- $\quad$ Trato a las personas en todo tipo de situaciones sociales.

- $\quad$ Cuando sea posible, formación pre-laboral.

Debemos prestar especial cuidado en favorecer que los aprendizajes que se han llevado a cabo no se extingan por falta de ocasiones para ponerlos en práctica. Las técnicas de modificación de conducta son eficaces y pueden servirnos de ayuda, tanto para la instauración de estas habilidades, como para la intervención frente a comportamientos autodestructivos o inadaptados.

Un objetivo prioritario con estos niños, dentro del ámbito psicosocial, es potenciar su autocontrol emocional. Para ello, debe fortalecerse su autoestima a través de nuestra valoración y afecto. Su integración y participación social están muy vinculadas a la adquisición de hábitos y habilidades de interacción, que van a ser sus recursos para 
el autocontrol emocional en los contextos sociales. Estas habilidades permitirán su normal participación en las actividades de su entorno, posibilitarán su aceptación por otras personas y evitarán su aislamiento.

El juego es una estrategia esencial para estimular el desarrollo psicosocialde estos niños. A través de él, se potencian los vínculos afectivos y sociales, al tiempo que se posibilitan las experiencias sensorio-motoras que sustentaran su desarrollo cognitivo. Todas las actividades cotidianas deben tener un componente lúdico y de comunicación afectiva. Cuando su desarrollo se lo permita, han de entrar en escena los objetos que le van a permitir explorar las características de su entorno físico y avanzar en su desarrollo cognitivo.

El momento de la escolarización también va a ser decisivo, ya que le va a permitir participar de un entorno social. Su momento de inicio hay que considerar las orientaciones de los especialistas que hacen el seguimiento del caso, escogiéndose el centro donde se va a llevar a cabo, y considerando los servicios y recursos de que dispone. Su posterior escolarización en las etapas obligatorias debe contar con una evaluación psicopedagógica y un dictamen de escolarización realizado por los servicios competentes de la administración autonómica.

Con carácter general dicha escolarización ha de ser lo menos restrictiva posible, considerando siempre las características y las necesidades que de ellas se derivan. Finalizando la escolaridad obligatoria, debe prepararse para una futura inserción sociolaboral a través de un concepto protegido de empleo.

Pautas para el aprendizaje:

- $\quad$ Las actividades tendrán un carácter lúdico con materiales educativos.

- $\quad$ Ambiente tranquilo y relajado.

- $\quad$ Confección de libretas con imágenes para la identificación de acciones, situaciones, personas...

- $\quad$ Buscar el momento en el que el niño esté más receptivo.

- $\quad$ La presentación de actividades se hará gradualmente: de sencillas a complejas.

- $\quad$ Basarnos en la motivación del niño, sin forzarle.

- $\quad$ Dejarle probar y experimentar.

- $\quad$ Ofrecerle la posibilidad de jugar libremente.

- $\quad$ Respetar los tiempos de aprendizaje.

- $\quad$ Tener en cuenta los diferentes ritmos de adquisición de los aprendizajes.

\section{-Evolución.}

El retraso evolutivo se hace evidente desde la etapa intrauterina. Posteriormente su desarrollo sigue siendo lento. La motricidad, el equilibrio y las capacidades intelectuales presentan un retraso significativo a medida que el niño va creciendo. De 
los 2 a los $5 / 6$ años, los niños suelen mantener la cara redondeada y la nariz corta con una hipotonicidad general lo que determina que sean sumamente frágiles a la hora de andar, mantener el equilibrio 0 efectuar cualquier actividad que tenga implicaciones motoras. La boca puede estar abierta. La mandíbula es pequeña, suele producir mal oclusión dental lo que dificulta el reflejo de morder y engullir la comida. Otra característica, señalada por muchos padres, es que no necesitan dormir mucho.

Es importante volver a señalar que las metas evolutivas que puedan alcanzar los afectados por el síndrome vendrán condicionados por tres aspectos fundamentales:

1 La magnitud de los daños estructurales en el brazo corto del Cromosoma 5 y delas zonas concretas afectadas. Ello nos marca un límite biológico en las metas a conseguir.

2. De la atención precoz suministrada así como de la atención y/o enseñanza recibida por parte de profesionales especializados.

3. De la respuesta del niño, por ejemplo: muestra interés por la interacción, curiosidad por el entorno, por el aprendizaje...son signos para un mejor pronóstico y evolución.

Aproximadamente la mitad de los niños adquieren habilidades verbales suficientes para comunicarse. A medida que se hacen mayores, los signos fenotípicos se hacen menos evidentes. Los niños establecen relaciones sociales con sus iguales, disfrutando en situaciones de juego pero con poco conocimiento o sentido del peligro y escasa capacidad de juicio racional. Como aspectos positivos mencionar que pueden tener una excelente memoria para situaciones o personas de interés especial, son buenos imitadores y pueden copiar modelos de otros niños.

En la vida adulta su estilo de vida variará en función del grado de funcionamiento autónomo, motor y cognitivo que ha asumido. Se están describiendo casos que tras un mal pronóstico evolutivo, el niño ha conseguido, mediante ayudas familiares y profesionales, un nivel de rendimiento superior a lo previsto. Se hacen necesarios más estudios al respecto para poder concretar estos aspectos.

\section{-El comportamiento.}

Se han descrito ya conductas positivas de interés por la socialización, sin embargo, hay otras conductas de tipo disruptivo, que pueden presentarse y ser susceptibles de tratamiento psicológico aunque suelen ser menos frecuentes si se logra un sistema de comunicación alternativo:

- $\quad$ Conductas disruptivas de arañar o morder a compañeros.

- $\quad$ Conductas auto-lesivas, arañazos, golpes en la cabeza, mordiscos en los brazos.

- $\quad$ Miedo a determinados objetos.

- $\quad$ Timidez ante situaciones nuevas o extraños con reacciones anómalas. 
- $\quad$ Conductas desafiantes.

-Orientaciones para la intervención.

Como la mayoría de síndromes, éste no tiene un tratamiento específico disponible. La intervención se necesitará de médicos para tratar los aspectos más orgánicos y psicólogos, fisioterapeutas, logopedas, psicomotricistas, asistente social, para los aspectos educativos y sociales.

Intervención con la família:

- $\quad$ Aceptación y comprensión del problema.

- $\quad$ Actuación precoz una vez confirmado el diagnóstico.

- $\quad$ Asumir el compromiso de buscar soluciones y tratamientos para los síntomas.

- $\quad$ Coordinación y complicidad con el equipo de profesionales.

Intervención psicológica y educativa con el niño:

A nivel conductual puede ser necesario la intervención con técnicas de modificación de conducta para reducir y/o eliminar las conductas disruptivas. Estas técnicas deberán serán personalizadas. Como parte del tratamiento, los padres deberán ser entrenados para poner en marcha en el ámbito familiar estas estrategias. También se deberá intervenir para establecer pautas y hábitos de autonomía como la alimentación, higiene, etc. El punto que más preocupa a las familias es que los niños con el síndrome sean incapaces de valerse por sí solos y desenvolverse socialmente cuando sean adultos.

El juego puede ser utilizado como medio motivador para la realización de las diferentes actividades. Éstas deben estar encaminadas a conseguir el éxito en un nivel creciente de dificultad. Un objetivo importante es el de asumir un canal comunicativo eficaz con el niño, ello supone un paso importante para la prevención de las conductas disruptivas, ya que el niño consigue comunicarnos de forma eficaz sus necesidades o deseos.

\section{0.-Conclusión.}

Me ha servido como formación profesional y de gran utilidad para indagar en las distintas fuentes de información incluyendo a los numerosos autores que hablan de manera dinámica y sugestiva de este síndrome. El objetivo que quería cumplir queda resuelto ya que he intentado globalizarlo de manera que todas las ideas y todos los puntos estén relacionados y enlazados.

Para terminar, aunque sea un síndrome poco frecuente y no ocurra en muchos casos, siempre está presente en nuestra sociedad y merece la pena estudiarlo e investigarlo. 
Me ha hecho mejor competente y dominante en este ámbito de la Educación Especial, por lo que espero que sirva de beneficio para el futuro.

\section{1.-Referencias.}

Carloni R. (2014). El síndrome del maullido de gato: Aspectos característicosy pautas educativas. Primera edición en español.

Chang, C.Y., Lin, S.P., Lin, HY., Chen, Y.J, Kao, H.A., Yeung, C.Y., et al.. (2007). Cri du chat syndrome. Acta Paediatrica Taiwanica, 48:328-31.

Chang, D.J. \& Boer, H. (1998). Problem behaviours associated with deletion PraderWilli, Smith-Magenis, and Cri du Chat Syndromes. American Journal of Mental Retardation, 103:264-271. https://doi.org/10.1352/08958017(1998)103<0264:PBAWDP>2.0.CO;2

Choong, Y.F., Watts, P., Little, E. \& Beck, L. (2003). Goldenhar and cri-duchatsyndromes: a contiguous gene deletion syndrome? J AAPOS, 7:226-227. https://doi.org/10.1016/S1091-8531(02)42019-8

Clarke, D.J. \& Boer, H. (1998). Problem behaviours associated with deletion PraderWilli, Smith-Magenis, and Cri du Chat Syndromes. American Journal of Mental Retardation, 103:264-271. https://doi.org/10.1352/08958017(1998)103<0264:PBAWDP>2.0.C0;2

Cornish K.M. \& Munir, F. (1998). Receptive and expressive speech skills in children with cri-du-chat syndrome. Journal Communication Disorders, 31:73-80. https://doi.org/10.1016/S0021-9924(97)00052-X

Cornish K.M., Bramble, D. Munir, F. \& Pigram, J. (1999). Cognitive functioning in children with typical cri du chat (5p-) syndrome. Developmental Medicine and Child Neurology 41 (4):263-6. https://doi.org/10.1017/S0012162299000559

Cornish, K.M. \& Pigram, J. (1996). Developmental and behavioural characteristics of cri-du-chat syndrome. Archives of Diseases in Child, 75, 448-440. https://doi.org/10.1136/adc.75.5.448

Dykens, E. M. \& Clarke, D.J. (1997). Correlates of maladaptive behaviour in individuals with $5 p$ - (cri du chat) syndrome. Develomental Medicine and Child Neurology, 39:752- 756. https://doi.org/10.1111/j.1469-8749.1997.tb07377.x

Echeverría, A. (2000). Síndrome de "maullido de gato", guía para padres y educadores. Santander: Consejería de Sanidad, Gobierno de Catabria.

Fundación Síndrome 5P-. Medlineplus. Recuperado de: http://fundacionsindrome5p.org/informacion sobre sindrome $5 \mathrm{p} /$ 
García Rodríguez, C., Foncubierta Fernández, P., González Ramos, A. and García Martínez, N. (2013). Síndrome del Maullido del Gato, trabajo estudiantes $2^{\circ}$ EducaciónEspecial. $2^{\circ}$ Educación Especial.

Hernández Fernández, Á., Herranz Fernández, J. and Álvarez Álvarez, C. (n.d.). Síndrome de maullido de gato. [ebook] Cantabria, pp.139-159. Available at: http://ardilladigital.com/DOCUMENTOS/DISCAPACIDADES/PSIQUICAS/SIND RO MES\%20Y\%20APOYOS\%20-\%20FEAPS\%20\%20libro/06\%20capitulo05\%20Sindrome\%20de\%20Maullido\%20de\%20Gato.p df [Accessed 17 Dec.2017].

Marco A. L (2005, Enero). Asociación para el Tratamiento de las personas con alteraciones en el desarrollo. Monográfico $\mathrm{n}^{07}$. Recuperado de: http://www.attem.com/libros/Mau.pdf

Martín, Cristina (2012, 19 marzo). Síndrome del maullido de gato (síndromedel cri-duchat). Recuperado 17 diciembre, 2017, de https://www.onmeda.es/enfermedades/sindrome_maullido_gato.html.

Rodriguez Caballero, A. (2012). Síndrome del Maullido del Gato (Tesis doctoral). Universidad de Sevilla, Sevilla https://asimaga.org/tesis-doctoral-sindrome-delmaullido-del-gato/

Síndrome de cri du chat, una rara cromosopatía. (2012). [ebook] Tegucigalpa, Honduras.: Blanca L. Galo,1 Ramón H. Alvarenga2, pp.17-19. Availableat: http://www.bvs.hn/RMH/pdf/2012/pdf/Vol80-1-2012-6.pdf [Accessed 17 Dec. 2017].

Wilkins, L. Brown, J. \& Wolf, B. (1982). Psychomotor development in 65 home-reared children with Cri-du-chat syndrome. Journal of Pediatrics, 97, 401-405. https://doi.org/10.1016/S0022-3476(80)80189-2

Wilkins, L. Brown, J. Nance, W. \& Wolf, B. (1982). Clinical heterogeneity in 86 homereared children with the Cri-du-chat syndrome. Journal of Pediatrics, 102, 528533. 